\title{
Análise do método de simulação de desempenho térmico da norma NBR 15.575
}

\author{
SORGATO, Márcio José ${ }^{1}$ \\ MELO, Ana Paula \\ LAMBERTS, Roberto \\ ${ }^{1}$ Universidade Federal de Santa Catarina, Florianópolis, Brasil. marciosorgato@labeee.ufsc.br
}

Resumo

As normas de desempenho de edificações avaliam e regulamentam o setor da construção civil, garantindo um padrão mínimo de qualidade e desempenho das edificações residenciais. $\mathrm{O}$ artigo tem como objetivo avaliar o método de simulação do desempenho térmico de edificações residenciais da NBR 15575. Observou-se que o método da norma apresenta limitações, avaliando o desempenho da edificação através de dias típicos de verão e inverno. Como proposta, foi desenvolvido e encaminhado um novo método de simulação durante a consulta pública da NBR 15575. A proposta do novo método busca avaliar o desempenho térmico da edificação através dos graus-hora de resfriamento e aquecimento. Os resultados da comparação entre estes dois métodos foram analisados, permitindo observar que o método de simulação da NBR 15575 atende ao desempenho térmico mínimo quando comparado com o sistema construtivo com paredes de concreto de $5 \mathrm{~cm}$ de espessura. Já com a aplicação do método proposto, observou-se que a edificação apresentou um desempenho térmico insatisfatório para o sistema construtivo analisado.

Palavras-Chave: simulação computacional, desempenho térmico, edificações residências.

\begin{abstract}
Buildings performance standards have as main purpose to evaluate and normalize the construction segment, ensuring a minimum quality and performance benchmark for residential buildings. Based on that, this study aims to apply and evaluate the simulation method presented in the NBR 15575 to assess the thermal performance of residential buildings. It was noticed that this method has limitations as it evaluates the building thermal performance based on summer and winter typical days. As a result, a new simulation method proposal was develop during the public consultation of the NBR-15575, which is based on heating and cooling degree-hour. The results from the comparison of both methods showed that the minimum requirement was achieved by the simulation method presented in NBR 15575 when compared with a concrete wall construction of $5 \mathrm{~cm}$. But, for the new method proposed it was observed an unsatisfactory thermal performance for the same wall construction.
\end{abstract}

Keywords: computer simulation, thermal performance, residential buildings. 


\section{Introdução}

A busca por soluções arquitetônicas energeticamente eficientes e climaticamente adequadas está sendo discutido no Brasil e no mundo (HENSEN e LAMBERTS, 2011). A preocupação com as condições de conforto ambiental das edificações vão desde a preservação dos recursos naturais até a fase de concepção. A prática de projetar com enfoque para o desempenho das edificações deve levar em consideração as características culturais e as condições climáticas, assim como os custos ambientais e econômicos (MELHADO, 2001).

As normas de desempenho das edificações avaliam e regulamentam desde os ganhos através das superfícies externas e aberturas existentes até as condições de ventilação do ambiente. Permitem identificar os materiais construtivos mais adequados à determinada edificação, de acordo com o clima em que está inserida.

A necessidade crescente de informações sobre a adequabilidade e o desempenho de novos produtos, e técnicas construtivas fez com que surgisse a necessidade da avaliação do desempenho destas soluções. Em alguns países, como Estados Unidos e França, já haviam instituído seus regulamentos de desempenho térmico e energético antes de 1990 (FRANÇA, 1988; ASHRAE, 1989). Segundo a pesquisa realizada por Janda e Busch (1992) com relação aos conteúdos das normas de desempenho, observou-se que a maioria dos países levou em consideração a combinação das exigências prescritivas e de desempenho no projeto.

A normatização do desempenho térmico de edificações no Brasil iniciou com o desenvolvimento da primeira norma de desempenho térmico para edificações, a NBR 15220 (ABNT, 2005) que estabelece critérios de acordo com parâmetros adequados a realidade brasileira. Devido à aplicação da NBR 15220 ser restrita para edificações unifamiliares de interesse social, iniciou-se o processo de desenvolvimento da norma de desempenho para edificações residenciais, a primeira versão foi publicada em 2008 da NBR 15575 (ABNT, 2008). Esta norma entrou em vigor em Maio de 2012, estabelecendo requisitos mínimos de desempenho, vida útil e de garantia para os sistemas que compõem as edificações. Alguns destes requisitos são: desempenho térmico; desempenho acústico; desempenho lumínico; e durabilidade. O setor da construção civil solicitou a revisão da norma em 2012, sendo que em fevereiro de 2013 foi publicada a versão final, entrou em vigor em julho de 2013.

A NBR 15575 (ABNT, 2013a) estabelece três procedimentos para a avaliação do desempenho térmico das edificações: simplificado, simulação e medição. No método simplificado, verifica-se o atendimento aos requisitos e critérios para fachadas e coberturas, estabelecidos na NBR 15575-4 (ABNT, 2008); e na NBR 15575-5 (ABNT, 2013c), para os sistemas de vedação e para os sistemas de cobertura. Caso a edificação não atinja os requisitos estabelecidos por este método, avalia-se pelo método de simulação ou medição. No método de simulação, verifica-se o atendimento aos requisitos e critérios estabelecidos na Parte 1 desta norma, por meio de simulação computacional do desempenho térmico da edificação. No método de medição, ocorre a verificação do atendimento aos requisitos e critérios estabelecidos também na Parte 1 desta norma, mas por meio da realização de medições em edificações ou em protótipos construídos.

Os métodos simplificados, apesar de fornecerem uma ferramenta rápida para a avaliação do desempenho da edificação, podem compreender uma incerteza considerável em seus resultados. Muitas vezes estes métodos podem comprometer o processo de análise da edificação em questão. Já o uso de programas de simulação energética para avaliação do desempenho exige um conhecimento muito amplo e complexo quando comparado ao método simplificado, porém a utilização deste método possibilita que o efeito de cada fator isoladamente seja analisado, o que nem sempre é possível em um caso real.

No trabalho realizado por Sorgato et. al., (2012) foram abordadas sugestões e críticas para a NBR 15575-1, NBR 15575-4 e NBR 15575-5 (ABNT, 2013a;b;c), no quesito desempenho térmico das edificações. Dentre as sugestões e críticas, ressalta-se o método de simulação da NBR 15575-1. Entre os pontos críticos observados, destacam-se a não avaliação do uso real da edificação sob análise e a não avaliação da influência da variação anual da temperatura no desempenho térmico da edificação.

Com base nessas observações, verifica-se a importância em aplicar e avaliar o método de simulação presente na NBR 15575-1, e com base nos resultados, propor um novo método de simulação para a análise do desempenho térmico das edificações residenciais.

\section{Objetivo}

Este artigo tem como objetivo avaliar o método de simulação presente na NBR 15575, analisando a proposta de um novo método de simulação para verificar o desempenho térmico de edificações residenciais. 


\section{Método}

Para a avaliação, o método de simulação presente na NBR-15575-1 foi comparado com o método proposto na consulta pública da norma (SORGATO et al., 2012). Foram simulados os mesmos casos conforme ambos os métodos, comparando os resultados referentes ao desempenho térmico da edificação.

\subsection{Características da modelagem da edi- ficação}

A avaliação do desempenho térmico foi realizada em uma edificação residencial unifamiliar com área construída de 36 m2, com dimensões de 6,0 m x 6,0 $m \times 2,8$ m. A edificação, localizada em Florianópolis, é composta por 2 dormitórios, banheiro, sala e cozinha conjugada. O projeto da edificação foi adaptado do programa Nova Casa da Companhia de Habitação do Estado de Santa Catarina (COHAB/SC). A Figura 1 apresenta o croqui em 3D e da planta baixa da edificação. A edificação foi modelada no programa EnergyPlus com cinco zonas térmicas, sendo quatro zonas para os ambientes e uma para o ático da cobertura.

\subsection{Propriedades da envoltória}

A cobertura é composta por telha cerâmica, barreira radiante de alumínio e laje de concreto. $\mathrm{O}$ valor da transmitância térmica da cobertura é de $\mathrm{UCOB}=1,09$ $\mathrm{W} / \mathrm{m} 2 \mathrm{~K}$, a capacidade térmica é de $113,0 \mathrm{~kJ} / \mathrm{m} 2 \mathrm{~K}$ e a absortância é de 0,50 . As paredes são de concreto armado moldadas in loco, com espessura total de 5 $\mathrm{cm}$. A transmitância térmica da parede é de UPAR=5,00 W/m2K, a capacidade térmica é de 120,0 $\mathrm{kJ} / \mathrm{m} 2 \mathrm{~K}$ e a absortância a radiação solar é 0,30 . O tamanho da abertura para ventilação e iluminação é de $15 \%$ em relação à área do ambiente, sendo que as aberturas dos ambientes de permanência prolongada possuem dispositivos de sombreamento externo (venezianas).

\subsection{Método de simulação do desempenho térmico presente na NBR-15575}

A norma estabelece que, caso não sejam atendidos os critérios de transmitância térmica e capacidade térmica do método simplificado, deve-se avaliar o desempenho térmico da edificação através do método de simulação computacional.

Para a análise do desempenho térmico foi adotado o programa de simulação computacional EnergyPlus versão 7.2. Este programa é validado pela ANSI/ ASHRAE Standard 140 (2011), atendendo o critério estabelecido na NBR 15575-1.

O desempenho térmico da edificação é avaliado para duas condições: desempenho de verão e desempenho no inverno. O critério da análise é baseado em valores máximos e mínimos de temperatura no interior dos ambientes de permanência prolongada (sala de estar ou dormitório).

A NBR 15575-1 (2013) estabelece que o desempenho da edificação seja avaliado em um ambiente de permanência prolongada (dormitório ou sala de estar) com maior número de paredes expostas para o exterior. Para avaliar o desempenho térmico para as condições de verão e inverno, esta norma recomenda adotar as condições mais críticas do ponto de vista térmico. Além disso, devem ser levados em consideração os dispositivos de sombreamento quando previstos em projeto.

\subsubsection{Critério de avaliação do desempenho térmico no verão}

O ambiente de permanência prolongada da edificação deve apresentar temperaturas menores ou iguais às externas, para o dia típico de verão. O pico da temperatura no interior do ambiente deve ser menor ou igual ao pico de temperatura do ar exterior. Para a cidade de Florianópolis, localizada na zona bioclimática 3 , o desempenho térmico do ambiente de

Figura 1: Croqui em 3D da edificação e croqui da planta baixa da edificação.
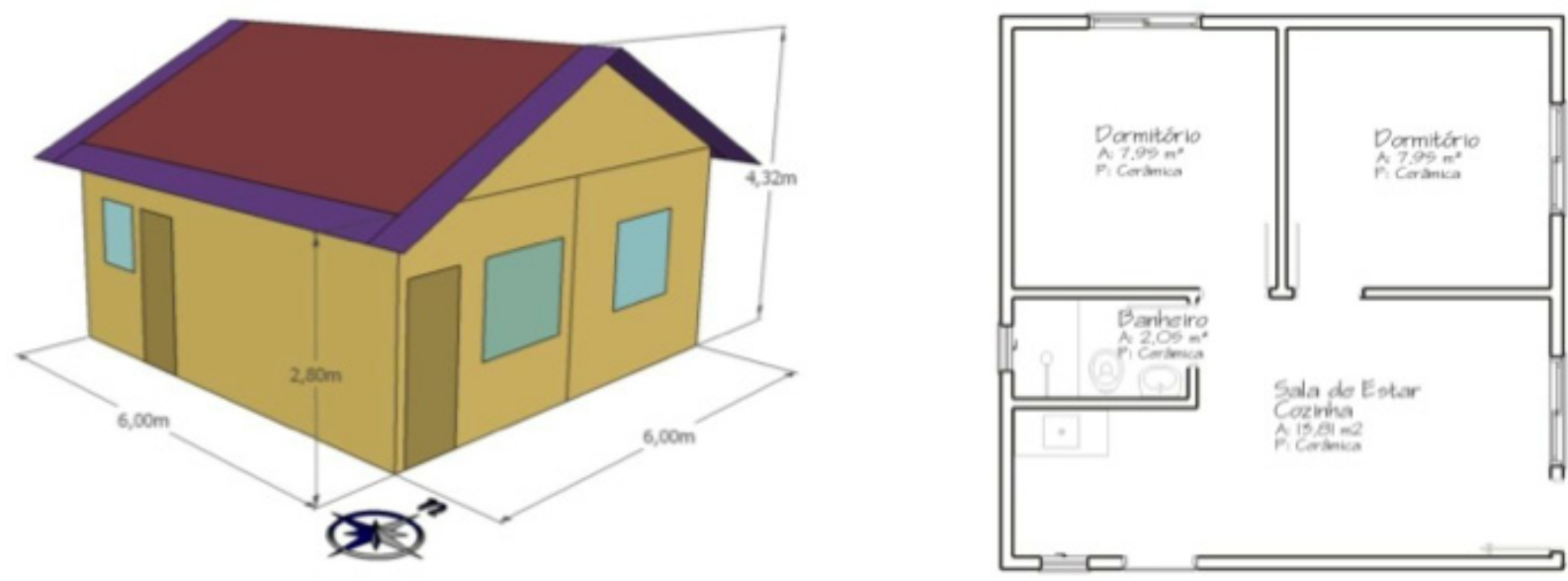
permanência prolongada é classificado em três níveis: mínimo, quando a temperatura interna máxima é menor ou igual à temperatura externa máxima (Tint $\leq$ Text); intermediário, quando a temperatura interna máxima do ambiente é menor que $2^{\circ} \mathrm{C}$ (Tint $\leq$ Text $2^{\circ} \mathrm{C}$ ); superior, quando a temperatura interna máxima do ambiente é menor que $4^{\circ} \mathrm{C}$ (Tint $\leq$ Text $-4^{\circ} \mathrm{C}$ ).

Para a avaliação do desempenho no verão, selecionou-se o dormitório com a janela orientada para oeste e a outra parede para norte. Para o período de verão, a edificação foi simulada sem cargas internas (ocupação, iluminação e equipamentos). A abertura está sombreada através de venezianas, no período do verão, das $8 \mathrm{~h}$ às $18 \mathrm{~h}$, conforme dispositivo de sombreamento previsto no projeto arquitetônico.

O desempenho térmico foi avaliado para o dia típico de verão para a cidade de Florianópolis, conforme os dados da Tabela A.2 da NBR-15575-1 (2013a). Segundo esta tabela, no dia típico de verão a temperatura máxima diária é de $32,7^{\circ} \mathrm{C}$, a amplitude diária da temperatura é de $6,6^{\circ} \mathrm{C}$, a temperatura de bulbo úmido é de $24,4^{\circ} \mathrm{C}$, e a nebulosidade é de 7 décimos. Ressalta-se que a Tabela A.2 da NBR 15575-1 não apresenta o valor da radiação solar.

Na simulação do dia típico de verão, três tipos de céu foram avaliados: $100 \%$ de céu limpo, 70\% de céu limpo e $30 \%$ de céu limpo. Também foi avaliada a influência da escolha da data na configuração do dia típico de verão, considerando simulações para o dia 21 de Dezembro (solstício de verão) e para o dia 05 de Março.

\subsubsection{Critério de desempenho no inverno}

As condições térmicas do ambiente de permanência prolongada da edificação para o desempenho de inverno devem apresentar valores mínimos diários da temperatura interna do ar maiores ou iguais à temperatura mínima externa, acrescida de $3^{\circ} \mathrm{C}$. $\mathrm{O}$ desempenho térmico do ambiente de permanência prolongada para a zona bioclimática 3 é classificado em três níveis: mínimo, quando a temperatura interna mínima é maior ou igual a $3^{\circ} \mathrm{C}$ da temperatura mínima externa (Tint $\geq$ Text $+3^{\circ} \mathrm{C}$ ); intermediário, quando a temperatura mínima no interior do ambiente é maior ou igual a $5^{\circ} \mathrm{C}$ da temperatura mínima externa (Tint $\geq$ Text $+5^{\circ} \mathrm{C}$ ); superior, quando a temperatura mínima no interior do ambiente é maior ou igual a $7^{\circ} \mathrm{C}$ (Tint $\geq$ Text+ $7^{\circ} \mathrm{C}$ ) para a zona bioclimática 3.

Para a avaliação do desempenho no inverno, selecionou-se o dormitório com a janela orientada para sul e a outra parede para leste. Conforme estabelecido na norma, foram simulados todos os ambientes da edificação com 1 (uma) renovação de ar por hora. Para o período de inverno, a norma não estabelece se a edificação deve ser avaliada com ou sem cargas internas (de ocupação e iluminação). Neste estudo foram simulados casos com e sem cargas internas. Para a simulação com cargas internas, adotou-se o mesmo padrão de ocupação e uso do sistema de iluminação artificial do método de simulação proposto.

\subsection{Método de simulação proposto}

\subsubsection{Edificação sob avaliação}

A modelagem da edificação sob avaliação deve estar de acordo com o projeto arquitetônico, geometria da edificação, aberturas, propriedades térmicas dos elementos construtivos (paredes, cobertura e piso) e a orientação conforme o projeto. As aberturas que proporcionam a ventilação (portas e janelas) devem possuir as mesmas coordenadas cartesianas do projeto sob avaliação.

\subsubsection{Cargas internas dos ambientes de per- manência prolongada}

Os ambientes de permanência prolongada da edificação devem ser simulados com as mesmas cargas internas de ocupação e iluminação para todo o ano, conforme são apresentados no padrão de ocupação e iluminação.

\section{a) Padrão de ocupação}

Para cada dormitório da edificação deve ser adotado o padrão de ocupação de duas pessoas, entre as $21 \mathrm{~h}$ e 7h. A sala de estar da edificação deve ser simulada com um padrão de ocupação de $50 \%$, entre às $14 \mathrm{~h}$ e $18 \mathrm{~h}$ e com $100 \%$ entre às $18 \mathrm{~h}$ e $21 \mathrm{~h}$.

A taxa metabólica para cada atividade é determinada em função do tipo de atividade desempenhada em cada ambiente. Para a atividade no dormitório (dormindo ou descansando), o valor de calor dissipado de $81 \mathrm{~W} /$ pessoa. Para a atividade na sala (sentado ou assistido televisão) o valor considerado é de 108 W/ pessoa.

Para os ambientes de permanência prolongada que não são dormitórios ou sala de estar, deve-se considerar o padrão de ocupação da sala de estar.

\section{b) Padrão de uso do sistema de iluminação}

O padrão de uso do sistema de iluminação está vinculado em função do padrão de ocupação dos ambientes de permanência prolongada. Considerase que os usuários utilizam a iluminação artificial nos dormitórios entre $6 \mathrm{~h}$ e $7 \mathrm{~h}$, e entre $21 \mathrm{~h}$ às $23 \mathrm{~h}$. Na sala de estar, os usuários utilizam a iluminação artificial durante o período das $17 \mathrm{~h}$ às $21 \mathrm{~h}$.

\subsubsection{Estratégia de Ventilação Natural}


A estratégia de ventilação natural é seletiva, permitindo abrir as janelas conforme os critérios de temperatura. As janelas são abertas quando a temperatura do ambiente é igual ou superior à temperatura de setpoint (Tint $\geq$ Tsetpoint), e também quando a temperatura do ambiente é superior à externa (Tint $\geq$ Text). A temperatura que que habilita a ventilação natural é de $20^{\circ} \mathrm{C}$ para todo o ano.

\subsubsection{Edificação de referência}

A modelagem da envoltória da edificação de referência deve atender os limites estabelecidos no método prescritivo da norma, para os valores de transmitância térmica da parede e cobertura conforme a zona bioclimática adotada. As aberturas dos dormitórios da edificação de referência devem ser modeladas com dispositivo de sombreamento. O período mínimo de sombreamento das aberturas estabelecidos para a zona bioclimática 3 é de 21 de Setembro a 20 de Março (no horário das $8 \mathrm{~h}$ às $18 \mathrm{~h}$ ), compreendendo as estações da primavera e do verão. Ressalta-se que a mesma estratégia de ventilação natural adotada para a edificação de referência deve ser adotada para a edificação sob avaliação.

\subsubsection{Critério de avaliação do desempenho térmico}

O desempenho da edificação ventilada naturalmente é avaliado através dos indicadores de graus-hora de resfriamento $\left({ }^{\circ} \mathrm{ChR}\right)$ e graus-hora de aquecimento $\left({ }^{\circ} \mathrm{ChA}\right)$. Os ${ }^{\circ} \mathrm{ChR}$ avalia o desempenho térmico da edificação para o calor, e os ${ }^{\circ} \mathrm{ChA}$ avalia o desempenho para frio.

Os ambientes de permanência prolongada são avaliados através da comparação entre o desempenho térmico da edificação sob avaliação com o desempenho térmico da edificação de referência.

Os indicadores de ${ }^{\circ} \mathrm{ChR}$ e ${ }^{\circ} \mathrm{ChA}$ dos ambientes de permanência prolongada da edificação sob avaliação devem ser iguais ou menores que os graus-hora de resfriamento e graus-hora de aquecimento da edificação de referência para que esta apresente desempenho satisfatório.

\section{a) Cálculo dos graus-hora de resfriamento}

Os ${ }^{\circ} \mathrm{Ch}_{\mathrm{R}}$ devem ser calculados com a temperatura de base de $26^{\circ} \mathrm{C}$. Através da Equação 1 , calcula-se 0 indicador de ${ }^{\circ} \mathrm{Ch}_{\mathrm{R}}$ para a temperatura operativa horária dos ambientes de permanência prolongada.

$$
{ }^{\circ} \mathrm{Ch}_{\mathrm{R}}=\sum\left(T_{o}-26^{\circ} \mathrm{C}\right)
$$

Onde:

${ }^{\circ} \mathrm{Ch}_{\mathrm{R}} \quad$ indicador de graus-hora para resfriamento;

$\mathrm{T}_{0} \quad$ temperatura operativa horária $\left({ }^{\circ} \mathrm{C}\right)$;

\section{b) Cálculo dos graus-hora de aquecimento}

Os ${ }^{\circ} \mathrm{Ch}_{\mathrm{A}}$ devem ser calculados com a temperatura de base de $18^{\circ} \mathrm{C}$. Através da Equação 2, calcula-se o indicador de ${ }^{\circ} \mathrm{Ch}_{\mathrm{A}}$ para a temperatura operativa horária dos ambientes de permanência prolongada.

$$
{ }^{\circ} \mathrm{Ch}_{\mathrm{A}}=\sum\left(18^{\circ} \mathrm{C}-T_{o}\right)
$$

Onde:

${ }^{\circ} \mathrm{Ch}_{\mathrm{A}}$ indicador de graus-hora de aquecimento; $\mathrm{T}_{0} \quad$ temperatura operativa horária $\left({ }^{\circ} \mathrm{C}\right)$;

\section{Análise dos resultados}

\subsection{Método de simulação do desempenho térmico presente na NBR-15575}

A Tabela A.2 e a Tabela A.3 referentes aos dados de dias típicos de inverno e verão da NBR 15575 (ABNT, 2013a) não apresentam opções para todas as zonas bioclimáticas brasileiras. Observa-se que para as zonas bioclimáticas 2 e 5 , a norma não estabelece uma cidade para avaliar o desempenho térmico. A norma também não apresenta o método para calcular o dia típico de projeto, inviabilizando a avaliação do desempenho térmico de edificações residenciais para estas zonas climáticas.

A Tabela A.3 do item "11- Desempenho térmico" da NBR-15575-1 (ABNT, 2013a) apresenta o critério de avaliação do desempenho térmico da edificação para condições de inverno. Este critério não se aplica para as zonas bioclimáticas 6,7 e 8 . Com base nesta definição, não tem justificativa para que a Tabela A.3 (Dados de dias típicos de inverno de algumas cidades brasileiras) apresente cidades das zonas bioclimáticas 6, 7 e 8, como, por exemplo, Aracaju e Belém.

Para as zonas bioclimáticas que não apresentam nenhuma cidade correspondente na Tabela A.2 e na Tabela A.3, como deverá o simulador proceder para avaliar o desempenho térmico da edificação? A norma não apresenta o método adotado para definição dos dias típicos de inverno e verão. Consequentemente, torna-se inviável para os profissionais realizarem o trabalho de acordo com um método padrão, pois cada simulador pode adotar um método para definir o dia típico em questão.

Nota-se também que as informações apresentadas na Tabela A.2 e na Tabela A.3 da NBR 15575-1 não são suficientes para realizar a simulação no programa de simulação computacional EnergyPlus, este recomendado pela norma. Para simular um dia de projeto (Design Day) é necessário inserir as seguintes informações sobre o arquivo climático: data, temperatura de bulbo seco, amplitude da temperatura de bulbo seco, uma condição de umidade (temperatura 
bulbo úmido ou temperatura de ponto de orvalho ou umidade relativa ou entalpia) no pico da temperatura de bulbo seco, pressão atmosférica, velocidade e direção do vento e especificar o modelo solar (tipo de céu) ou dados horários de radiação direta e difusa. $A$ Tabela A.2 e a Tabela A.3 da NBR-15575-1 não apresentam informações referentes à data, a velocidade e direção dos ventos e o tipo de céu para simular um dia de projeto.

Figura 2: Influência da data no dia típico de verão.

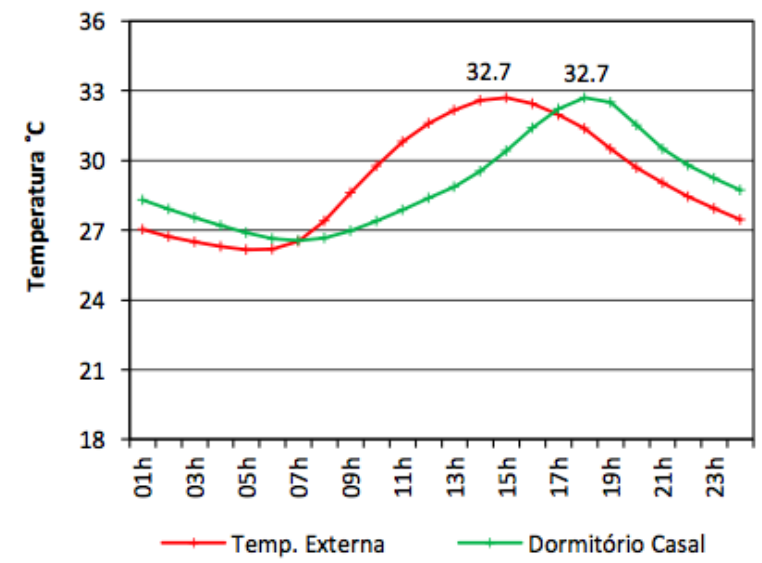

(A)

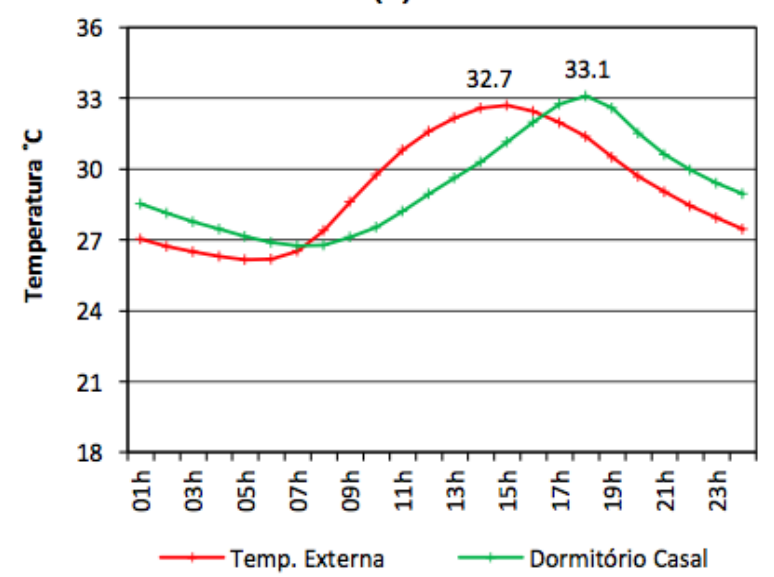

(B)

Sattler (1989) menciona que é importante definir a data de referência do dia típico para que se estime com precisão os valores de irradiância solar nos diferentes componentes externos da edificação, uma vez que a declinação solar pode interferir nos resultados. A Figura 2 avalia a influência da definição da data na configuração do dia de projeto (Design Day) no programa de simulação EnergyPlus: na parte (A), a data determinada para o dia de projeto foi $21 \mathrm{de}$ Dezembro (solstício de verão); na parte (B), a data foi dia 05 de Março. Observa-se que a alteração da data resultou em uma diferença de temperatura interna no dormitório de $0,4^{\circ} \mathrm{C}$, ou seja, a simples alteração da data do dia típico pode aprovar um sistema construtivo de acordo itens estabelecidos na NBR 15575-1. Como a norma não define a data do dia de projeto que deve ser considerada, os resultados podem ser diferentes dependendo de como o simulador configura o dia de projeto. Neste estudo, apresenta-se uma análise de duas datas na estação de verão.

Figura 3: Influência do tipo de céu na simulação no dia típico de verão.

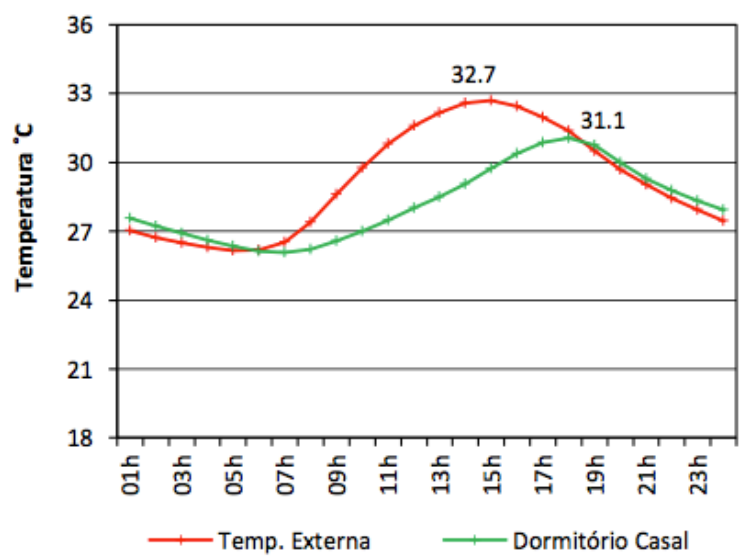

(A)

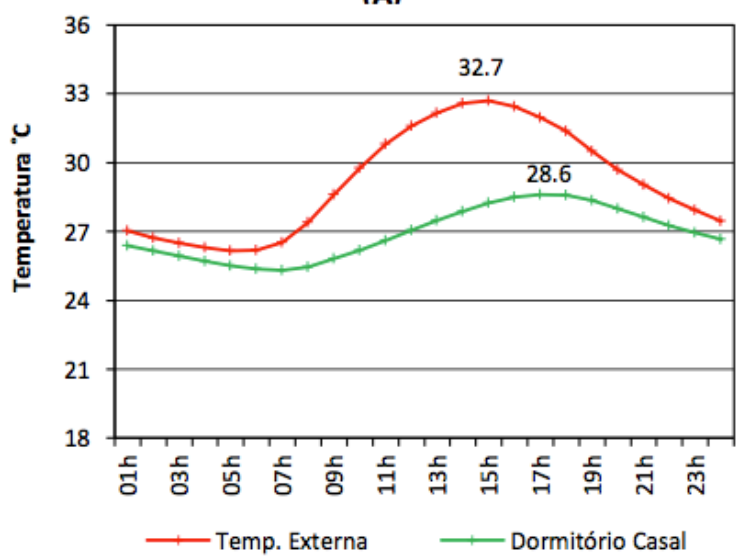

(B)

A maioria das cidades listadas na Tabela A.2 e na Tabela A.3 (NBR-15575-1) apresentam valores de radiação solar e nebulosidade em décimos, o que torna inviável levar em consideração no programa de simulação sem interpretações e deduções do simulador. Estas tabelas também não informam a qual radiação solar refere-se: a global horizontal, direta normal ou a difusa. Sem esta informação, o simulador tem que deduzir como utilizá-la. Em relação à informação referente à nebulosidade da norma, esta não tem aplicação direta na configuração do dia de projeto. Para a simulação através do programa recomendado pela norma (EnergyPlus), seria importante definir o tipo de céu que deve ser utilizado na simulação para que todas as edificações sejam analisadas na mesma condição. A interpretação do simulador referente às informações da nebulosidade e da radiação solar pode interferir nos resultados da simulação. A influência das diferentes opções de configuração do tipo de céu na simulação é apresentada na Figura 2 (A) e Figura 3. O resultado da simulação com a configuração de céu limpo é apresentado na Figura $2(\mathrm{~A})$, na qual a temperatura do dormitório foi igual à temperatura do ambiente externo, em $32,7^{\circ} \mathrm{C}$. O resultado da simulação do dia de projeto com a configuração de $70 \%$ de céu limpo é apresentado na Figura $3(\mathrm{~A})$, na qual a temperatura 
dormitório foi $31,1^{\circ} \mathrm{C}$ : uma diferença de $1,6{ }^{\circ} \mathrm{C}$ em relação à configuração $100 \%$ de céu limpo. A Figura 3 (B) apresenta o resultado com a configuração do dia de projeto com $30 \%$ de céu limpo. Observa-se que a temperatura máxima interna do dormitório foi de 28,6 ${ }^{\circ} \mathrm{C}$, apresentando uma diferença $4,1{ }^{\circ} \mathrm{C}$ entre a configuração de $100 \%$ de céu limpo. Estes resultados mostram a importância da configuração do tipo de céu na simulação. Desta forma, é de extrema importância que a norma estabeleça o parâmetro do tipo de céu nas tabelas de dias típicos de verão. No dia típico de inverno a influência do tipo de céu é menor que no verão, devido à temperatura mínima ocorrer durante o período da madrugada.

Figura 4: Influência das cargas internas na simulação do dia típico de inverno.

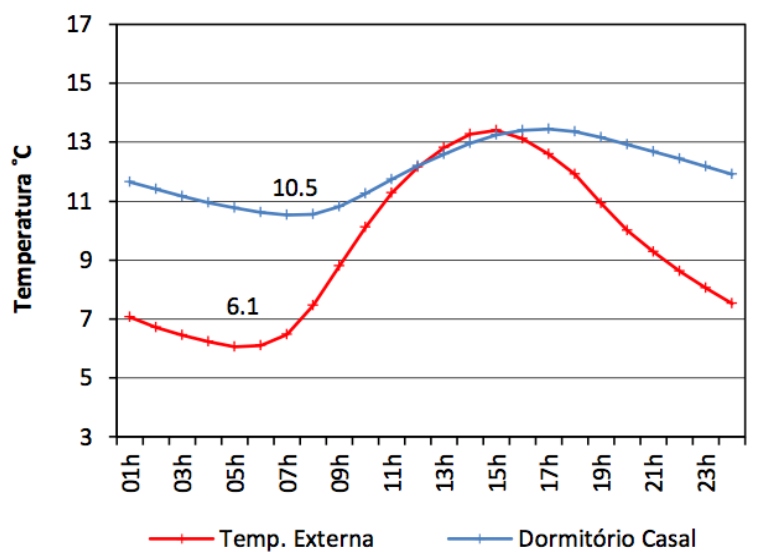

(A)

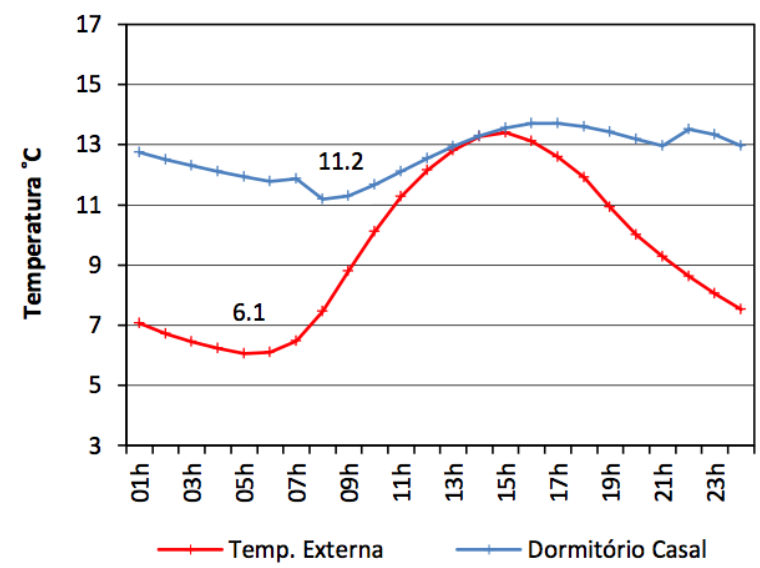

(B)

Na avaliação do desempenho térmico para o dia típico de verão, a norma recomenda que o modelo seja simulado sem cargas internas (ocupação, iluminação e equipamentos). Porém, a norma não recomenda a não utilização das cargas internas para o dia típico de inverno. A Figura 4 apresenta os resultados das simulações para o dia típico de inverno com e sem cargas internas. Observa-se que a simulação com carga interna (Figura 4 B) apresenta temperaturas internas maiores que o caso sem carga interna (Figura 4 A). A diferença encontrada na temperatura interna mínima entre os casos é de $0,70^{\circ} \mathrm{C}$. O método estabelecido pela NBR-15575-1 para avaliar o desempenho térmico da edificação para a condição de inverno não garante que a edificação será confortável, devido ao ambiente apresentar baixas temperaturas internas. O método estabelecido pela norma prevê uma avaliação fora da realidade de uso da edificação, pois geralmente o usuário permanece com as aberturas da edificação fechadas no período de frio. Portanto, pode-se concluir que 1 (uma) renovação de ar por hora está prejudicando o desempenho da edificação.

\subsection{Novo Método de simulação proposto}

Os resultados da avaliação do desempenho térmico da edificação através do método de simulação proposto são apresentados na Figura 5. Observa-se que o desempenho térmico da edificação com parede de concreto de $5 \mathrm{~cm}$ (parede sob avaliação) apresentou os ${ }^{\circ} \mathrm{Ch}$ de aquecimento de aproximadamente $60 \%$ superior quando comparado com a edificação com a parede de referência. Os ${ }^{\circ} \mathrm{Ch}$ de aquecimento referem-se ao desempenho da envoltória da edificação para condição de frio (inverno). O desempenho para a condição de calor é avaliado através dos ${ }^{\circ} \mathrm{Ch}$ de resfriamento. Neste caso, a edificação com a parede de referência também obteve um desempenho térmico melhor: a edificação com parede de concreto de $5 \mathrm{~cm}$ apresentou ${ }^{\circ} \mathrm{Ch}$ de resfriamento de aproximadamente $70 \%$ superior que a edificação com a parede de referência.

O desempenho térmico de edificações residenciais deve ser avaliado levando em consideração a realidade de uso, com as cargas internas de ocupação e iluminação, e a estratégia de ventilação conforme os hábitos culturais da região. Através da simulação anual, é possível avaliar adequadamente as estratégias bioclimáticas para o clima que a edificação está inserida. Já através da simulação por meio do dia típico de inverno e verão, não é possível avaliar adequadamente as estratégias bioclimáticas, por simular uma condição extrema, na qual a frequência de ocorrência do dia típico durante o ano é pequena. O uso de dia típico de verão e inverno em simulação computacional está relacionado ao dimensionamento de equipamentos para condicionamento artificial, no qual os projetistas adotam condições extremas de temperatura para garantir que o equipamento em questão atenda a pior situação. Para a simulação de desempenho térmico o uso de dia típico não é adequado, pois desconsidera a influência da variação do clima, que em algumas regiões do Brasil são relevantes. 
Figura 5: Desempenho térmico da edificação de referência versus edificação com parede de concreto $5 \mathrm{~cm}$.

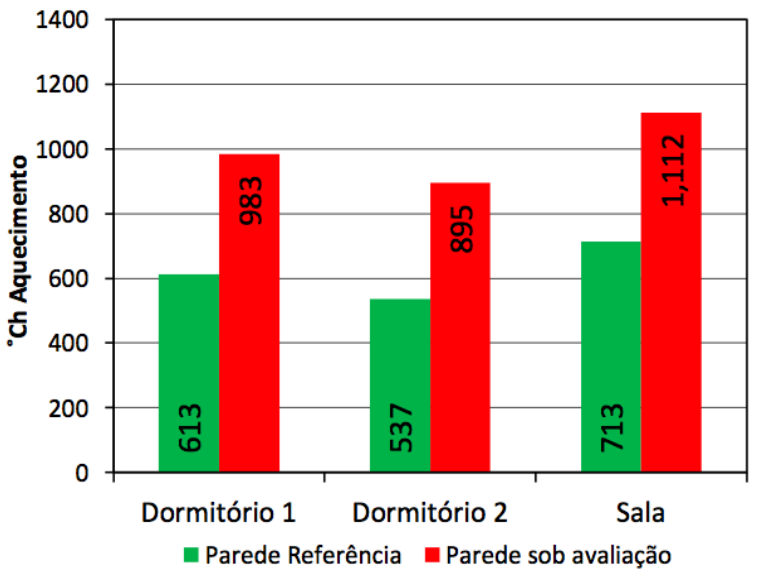

(A)

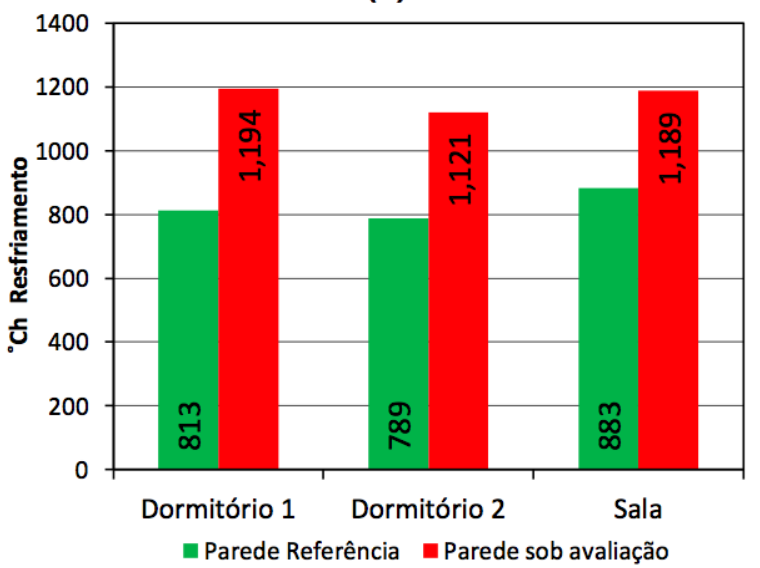

(B)

\section{Conclusões}

A avaliação do desempenho térmico de edificações residências pelo método de simulação da NBR-155751 (ABNT, 2013a) pode apresentar diferentes resultados, dependendo de como são configurados os dias típicos de verão e de inverno. As tabelas de dias típicos presentes nesta norma não apresentam opções de cidades para todas as zonas bioclimáticas brasileiras, assim como não apresentam informações importantes para a simulação por meio do dia de projeto. O tipo de céu e a data do dia típico de projeto influenciam na irradiação solar que atinge as superfícies da edificação, sendo que a simples alteração em um desses parâmetros pode viabilizar a aprovação de um sistema construtivo.

A norma recomenda que a edificação seja avaliada no dia típico de verão sem cargas internas (ocupação, iluminação e equipamentos). Porém, esta condição está fora da realidade das condições de uso das edificações residenciais, influenciando para que o desempenho térmico das edificações construídas seja completamente diferente do estimado pelo do método de simulação da NBR-15575. No dia típico de inverno, a norma não estabelece que a edificação deve ser simulada sem cargas internas. A comparação das simulações com e sem cargas internas para o dia típico de inverno resultou em uma diferença de $0,70^{\circ} \mathrm{C}$ na temperatura interna do dormitório.

A taxa de renovação de ar estabelecida pelo método da norma para os dias típicos de verão e de inverno não está de acordo com a realidade de uso das edificações residenciais. A condição estabelecida na NBR-15575 avalia as edificações fora da realidade de uso: no dia típico de inverno, a condição está prejudicando o desempenho; para o dia típico de verão, a condição de 1 (uma) renovação de ar está subestimando a ventilação natural.

Os resultados das simulações mostraram que 0 sistema construtivo com paredes de concreto $(5 \mathrm{~cm}$ de espessura) atende o desempenho térmico mínimo estabelecido na NBR-15575 pelo método de simulação. Quando comparado o desempenho térmico do sistema construtivo com paredes de concreto, através do método de simulação proposto, observa-se que a edificação tem um desempenho térmico insatisfatório em relação ao modelo de referência.

A simulação do desempenho térmico por meio do dia típico desconsidera a influência da variação do clima, que é importante para algumas regiões do Brasil. A edificação deve ser avaliada considerando a realidade de uso, com as cargas internas (ocupação e iluminação) e estratégia de ventilação natural conforme as preferências e hábitos culturais da população. Pela avaliação anual, é possível avaliar adequadamente as estratégias bioclimáticas para o clima que a edificação está inserida. O método proposto busca avaliar o desempenho térmico, considerando a realidade de uso das edificações residenciais.

\section{Referências Bibliográficas}

ABNT. NBR 15220-3: Desempenho térmico de edificações, parte 3 : zoneamento bioclimático brasileiro e diretrizes construtivas para habitações unifamiliares de interesse social. Rio de Janeiro: Associação Brasileira de Normas Técnicas 2005.

NBR 15575-4: Edifícios habitacionais de até cinco pavimentos - Desempenho : parte 4 : sistemas de vedações verticais externas e internas. Rio de Janeiro: Associação Brasileira de Normas Técnicas 2008.

NBR 15575-1: Edifícios habitacionais Desempenho: Parte 1 : Requisitos gerais. Rio de Janeiro: Associação Brasileira de Normas Técnicas 2013a.

NBR 15575-4: Edifícios habitacionais Desempenho : parte 4 : Sistemas de vedações verticais externas e internas. Rio de Janeiro: ABNT 2013b. 
NBR 15575-5: Edifícios habitacionais Desempenho : parte 5 : Requisitos para sistemas de coberturas: ABNT 2013c.

ASHRAE. ASHRAE 90.1-1989: Energy standard for buildings except low-rise residential buildings. Atlanta, GA: American Society of Heating, Refrigerating and Air-Conditioning Engineers 1989.

ASHRAE 140-2011: Stadard Method of Test for the Evaluation of Building Energy Analys Computer Programs. Atlanta, GA: American Society of Heating, Refrigerating and Air-Conditioning Engineers, Inc. 2011.

FRANÇA. Arrêté du 13 avril 1988. Relatif aux équipements et aux caractéristiques thermiques dans les bâtiments à usage de bureaux ou de commerce. Paris: Journal Officiel de la République Française 1988.

HENSEN, J. L. M.; LAMBERTS, R. Building Performance Simulation for Design and Operation. Routledge, 2011.

JANDA, K. B.; BUSCH, J. F. Worldwide status of energy standards for buildings. Summer Study on Energy

Efficiency in Buildings. Berkeley: ACEEE. V. 6: 103 a 105 p. 1992.

MELHADO, S. B. Gestão, cooperação e integração para um novo modelo voltado à qualidade do processo de projeto na construção de edifícios. 2001. Tese (Livre-Docência). Escola Politécnica, Universidade de São Paulo, São Paulo.

SATTLER, M. A. Dias Climáticos Típicos para o Projeto Térmico de Edificações em Porto Alegre. Porto Alegre: CIENTEC 1989.

SORGATO, M. J. et al. Nota técnica referente à avaliação para a norma de desempenho NBR 15575 em consulta pública. Universidade Federal de Santa Catarina. LABEEE - Laboratório de Eficiência Energética em Edificações. 2012. 